\title{
A Randomized, Double-Blind, Placebo-Controlled Trial of Ibuprofen Lysinate in Comparison to Ibuprofen Acid for Acute Postoperative Dental Pain
}

\author{
Ján Kyselovič · Eva Koscova · Anette Lampert · Thomas Weiser
}

Received: October 14, 2019 / Published online: January 7, 2020

(C) The Author(s) 2020

\begin{abstract}
Introduction: Ibuprofen acid is poorly soluble in the stomach, thus reaching maximum plasma levels at approximately $90 \mathrm{~min}$ postdose. Ibuprofen lysinate has been developed to accelerate absorption of ibuprofen to shorten the time to analgesic efficacy. This study compared analgesic efficacy and onset of effect of a single dose of ibuprofen lysinate or ibuprofen acid in patients undergoing third molar extraction.
\end{abstract}

Enhanced Digital Features To view enhanced digital features for this article go to: https://doi.org/10.6084/ m9.figshare.11395770.

Electronic supplementary material The online version of this article (https://doi.org/10.1007/s40122019-00148-1) contains supplementary material, which is available to authorized users.

J. Kyselovič

Clinical Research Unit, 5th Department of Internal Medicine, Medical Faculty of Comenius University, University Hospital, Bratislava, Slovak Republic

E. Koscova

CHC Medical Affairs, Eastern Europe Zone, SanofiAventis Pharma Slovakia s.r.o, Bratislava, Slovak Republic

\section{A. Lampert · T. Weiser ( $\square)$}

Medical CHC, Sanofi-Aventis Deutschland GmbH, Industriepark Höchst, Frankfurt, Germany

e-mail: thomas.weiser@sanofi.com
Methods: Randomized, double-blind, placebocontrolled, multi-center, parallel-group singledose study. Adults (18-60 years) undergoing extraction of $\geq 1$ third molar were randomized 2:2:1 to ibuprofen lysinate, ibuprofen acid, or placebo postoperatively. Pain relief (PAR, 5-point scale, $0=$ none to $4=$ complete pain relief) and pain intensity (PI, $100 \mathrm{~mm}$ visual analog scale) were assessed between 15 and 360 min post-dose. The primary endpoint was the weighted sum of PAR scores at $6 \mathrm{~h}$ (TOTPAR). Time to onset of effect, global assessment of efficacy, and adverse events were also assessed.

Results: Overall, 351 patients received ibuprofen lysinate $(N=141)$, ibuprofen acid $(N=139)$, or placebo $(N=71)$. Both active treatments significantly reduced pain compared with placebo, from $15 \mathrm{~min}$ post-dose to $6 \mathrm{~h}$ (TOTPAR: ibuprofen lysinate: 19.57; ibuprofen acid: 19.96; placebo: 8.27). Ibuprofen lysinate was significantly more effective than placebo, but noninferior to ibuprofen acid, at providing pain relief over $6 \mathrm{~h}$. There was no significant difference between ibuprofen lysinate and ibuprofen acid for onset of analgesia. Both ibuprofen formulations were well tolerated; all adverse events were mild to moderate and considered unrelated to treatment.

Conclusions: A single dose of ibuprofen lysinate is non-inferior to ibuprofen acid in terms of analgesic efficacy, onset of action, and tolerability in patients who have recently undergone dental surgery. 
Trial Registration: EudraCT No. 2006-00694233.

Plain Language Summary: Plain language summary available for this article.

Keywords: Dental pain; Ibuprofen acid; Ibuprofen lysinate; Ibuprofen lysine; Postoperative dental pain; Pain intensity; Pain relief

\section{Key Summary Points}

Why carry out this study?

Ibuprofen acid is poorly absorbed, taking approximately $90 \mathrm{~min}$ to reach maximum plasma concentrations, so alternative formulations (including ibuprofen lysinate) have been designed to be more rapidly absorbed and therefore provide a faster onset of analgesia.

This randomized, double-blind, placebocontrolled study evaluated the efficacy and safety of ibuprofen lysinate and ibuprofen acid for postoperative analgesia in adults undergoing third molar extraction.

\section{What was learned from the study?}

Both ibuprofen formulations were similarly effective in providing pain relief from $15 \mathrm{~min}$ to $6 \mathrm{~h}$ post-dose, and ibuprofen lysinate was non-inferior to ibuprofen acid in terms of analgesia over $6 \mathrm{~h}$.

Both ibuprofen formulations were well tolerated, with all adverse events being mild or moderate and unrelated to treatment.

These findings demonstrated that ibuprofen lysinate is non-inferior to ibuprofen acid in terms of analgesic efficacy, onset of action, and tolerability in patients with postoperative dental pain.

\section{PLAIN LANGUAGE SUMMARY}

Ibuprofen is a common pain reliever for people with mild to moderate pain, but it takes a while to start working because it is not absorbed into the bloodstream very quickly. Researchers have developed several different formulations of ibuprofen, designed to be absorbed more rapidly and therefore to start providing pain relief sooner after being taken. One of these formulations is called ibuprofen lysinate, and it is absorbed more quickly than standard ibuprofen on an empty stomach. This study looked at how well a single dose of ibuprofen lysinate relieved pain after dental surgery (wisdom tooth removal) and compared it with a single dose of standard ibuprofen and placebo. One of the key questions researchers wanted to answer was whether ibuprofen lysinate started relieving pain more quickly than standard ibuprofen. The study found that the two ibuprofen formulations were both significantly more effective than placebo for relieving pain after wisdom tooth removal, but ibuprofen lysinate was not more effective, or faster acting, than standard ibuprofen.

\section{INTRODUCTION}

Ibuprofen is a well-accepted and widely used nonsteroidal anti-inflammatory drug (NSAID) to treat acute mild to moderate pain [1-3]. However, as an acid, ibuprofen exhibits poor solubility in aqueous physiological environments and does not dissolve easily in the stomach, reaching maximum plasma levels at about 90 min after oral administration [4]. Fast onset of analgesic action is one prerequisite for successful treatment of acute pain [5]. Extensive research has been undertaken into the development of new formulations of ibuprofen with rapid absorption and improved oral bioavailability [6]. These formulations include an effervescent tablet, liquid, or arginine or lysine salt; maximum plasma levels with these formulations are reached between 29 and $40 \mathrm{~min}$ after administration, compared with the standard $90 \mathrm{~min}$ for ibuprofen acid when taken on an empty stomach (i.e., usually after $>10 \mathrm{~h}$ of 
fasting) $[4,7]$. The ultimate goal of research into new ibuprofen formulations is to reduce the time required for maximum uptake of ibuprofen, because this period of time is thought to be directly proportional to the rate of onset of analgesic effects $[4,5]$.

A meta-analysis by Moore et al. [4] showed that fast-dissolving ibuprofen appeared to be more efficacious than ibuprofen acid, but included only a small number of head-to-head efficacy studies. In addition, the efficacy studies in this analysis compared ibuprofen arginate with ibuprofen acid, and none investigated ibuprofen lysinate [4]. Therefore, we conducted a randomized, controlled trial to directly compare the efficacy and onset of analgesic action of ibuprofen lysinate with those of ibuprofen acid and placebo in patients undergoing third molar extraction. Surgical removal of impacted third molars is a pain model used extensively to evaluate analgesic efficacy of NSAIDs because it employs a standardized surgical procedure that generally requires only local anesthetics but results in substantial postoperative pain for up to $48 \mathrm{~h}$ after surgery [8-10]. The aim of the present clinical study was to evaluate the analgesic efficacy and onset of action of single doses of ibuprofen lysinate (Ibalgin Extra Fast ${ }^{\circledR}$ ) compared with placebo and with standard ibuprofen acid (Nurofen Forte ${ }^{\circledR}$ ) 400 mg after dental impaction surgery.

\section{METHODS}

This randomized, double-blind, double-dummy (placebo-controlled), multi-center, parallelgroup, single-dose study (EudraCT No.: 2006-006942-33) was conducted at nine centers in the Czech Republic between May 2007 and December 2007. All procedures were conducted in accordance with the ethical principles of the Declaration of Helsinki, International Committee on Harmonisation Good Clinical Practice Guidelines of 1997, and applicable national laws. The study began only when all the requirements of the appropriate regulatory authority had been fulfilled, and the study protocol had been approved by local ethics committees (see Supplementary Material).
Informed consent was obtained from all patients included in the study.

\section{Study Participants}

Eligible study participants were healthy men and women (aged 18-60 years) scheduled to undergo outpatient surgical removal of one or more third molars, at least one of which was impacted in bone. To be eligible for inclusion, patients agreed not to take analgesics other than protocol-defined rescue analgesics during treatment, anti-inflammatory drugs, sedativehypnotics, or antidepressants, tranquilizers, alcohol- or caffeine-containing beverages up to $6 \mathrm{~h}$ post-dose. Patients qualified for being treated with the test drugs when their baseline pain intensity (PI) exceeded $50 \mathrm{~mm}$ on a $100-\mathrm{mm}$ visual analog scale (VAS).

Patients were excluded if they had used any analgesics, anti-inflammatory drugs, sedativehypnotics, or antidepressants, tranquilizers, alcohol- or caffeine-containing beverages from midnight of the night prior surgery. Additionally, patients were ineligible to participate if there was the acute purulent inflammation in the area of the planned bone-impacted third molar removal; another acute or chronic painful physical condition; history or presence of significant organ disease. Other exclusion criteria were the presence, or recent history, of active peptic ulcer disease or gastrointestinal bleeding, any clotting or hematogenesis disorder, and, in women, pregnancy or breastfeeding. Finally, patients were excluded if they had any other disease or condition that may interfere with study assessments as judged by the investigator or were taking part in any other clinical trial or had participated in a clinical trial within the previous 3 months.

\section{Study Design}

Patients were randomized in a 2:2:1 ratio to ibuprofen lysinate $683 \mathrm{mg}$ (corresponds to ibuprofen acid $400 \mathrm{mg}$ ), ibuprofen acid $400 \mathrm{mg}$, or placebo, using random permutated blocks. No detailed information (including block size) was available to the investigators, who were 
provided with random numbers from a pseudorandom number generator.

Patients were randomized on the day of surgery (day 1) and received a single dose of the study medication once the effects of the local anesthetic effects had worn off, as long as the PI was $\geq 50 \mathrm{~mm}$ on the pain VAS. Because ibuprofen lysinate and ibuprofen acid tablets are not identical in shape and weight, dummy tablets of the alternative agent were used to maintain blinding. In the ibuprofen lysinate group, patients received ibuprofen lysinate $683 \mathrm{mg}$ and placebo of the ibuprofen acid tablet as dummy. In the ibuprofen acid group, patients received ibuprofen acid $400 \mathrm{mg}$ and placebo of the ibuprofen lysinate tablet as dummy, and in the placebo group, patients received both placebo tablets. The medication was presented to the patient by the study nurse (not the investigator) in indistinguishable vials containing two tablets in separate blister packs to maintain blinding. The nurse watched the patient take the medication with water to ensure compliance. The patients and investigators were blinded to the study medication. Patient assessments were undertaken at regular intervals for $6 \mathrm{~h}$ after drug administration, and patients returned to the study center 2 days later (day 3) for further assessment of efficacy and safety. Patients who did not achieve adequate pain relief were permitted to take rescue medication (paracetamol 500-1000 mg).

\section{Outcomes and Endpoints}

The primary objective was to demonstrate that: (1) ibuprofen lysinate is superior to placebo in overall analgesic efficacy; (2) ibuprofen lysinate is non-inferior to ibuprofen acid (the active comparator) in overall analgesic efficacy; and (3) ibuprofen lysinate is superior to ibuprofen acid in the onset of action. Secondary objectives were to assess the superiority of ibuprofen acid over placebo in total pain relief (TOTPAR), and other parameters of efficacy, such as global assessment, time to pain half gone, time to any pain relief, time to meaningful pain relief, and sum of the pain intensity difference (SPID).
Patients were asked to rate their pain relief (PAR) and PI at regularly scheduled intervals $(15,30,45,60$, and $90 \mathrm{~min}$ and 2, 3, 4, 5, and $6 \mathrm{~h})$. PAR was rated on a standard five-point scale (where $0=$ none; $1=$ a little; $2=$ some; $3=$ a lot; and $4=$ complete pain relief), while PI was rated on a $100 \mathrm{~mm}$ VAS (boundaries of the scale were marked none and severe). The primary efficacy endpoint was the TOTPAR comprising the weighted sum of the PAR scores at $6 \mathrm{~h}$. The difference of one point in PAR represents the minimum detectable pain difference for a patient. Thus, a value of 6 for TOTPAR was the minimum detectable pain difference over the $6-\mathrm{h}$ observation period. The equivalence limit was set a priori to -3 (i.e., TOTPAR difference). The PI difference (PID) was calculated by subtracting the pain intensity at each time point from the baseline pain intensity. The overall SPID was calculated as the weighted sum of the PID scores at $6 \mathrm{~h}$ post-dose. Time to pain half gone was calculated from the VAS pain intensity assessment.

Patients were asked for global assessment of study medication at the conclusion of the 6-h study period (or when the patient took rescue medication or at the time of premature termination, depending on what occurred first). Patients rated their pain medication on a fivepoint scale in response to the question "How would you rate the study medication you received for pain?", where $0=$ poor, $1=$ fair, 2 =good, 3 = very good, and $4=$ excellent . Patients were asked to record the onset of analgesia by noting the time to any pain relief (defined as the first perceptible pain relief), and time to meaningful pain relief, irrespective of the given (regular) time intervals for pain assessment. The use of rescue medication was also recorded.

The safety of ibuprofen lysinate and ibuprofen acid relative to placebo was assessed based on the incidence of adverse events (AEs) reported by patients on the day of surgery and at the follow-up visit. AEs were elicited using a standard non-misleading question such as "How did you feel since the last visit?". In addition, any signs or symptoms were observed. 


\section{Statistical Analysis}

The study aimed to enroll 350 patients. For the power analysis, it was assumed that both active treatments have the same overall analgesic efficacy and that the aim was to reject the null hypothesis of inferiority of the test drug. Based on published data, true TOTPAR was assumed to be 14 with a standard deviation of 7 . Provided that non-inferiority margin is - 3, 116 evaluable subjects per treatment group were required to achieve power of $90 \%$ at the $\alpha=0.05$ significance level (two-sided). A surplus of $20 \%$ was added because of possible protocol violators and the total number was rounded up to 140 enrolled subjects in either active treatment group [11-14]. With 140 patients in each active treatment arm, the minimum detectable difference with power of $\geq 80 \%$ was about $10 \mathrm{~mm}$.

Pain parameters (TOTPAR, PID, SPID, and time-specific PAR and PID scores) were analyzed using an analysis of variance (ANOVA) model including terms for treatment group, center, and sex. The proportions of patients in individual categories of global assessment of medications were summarized by treatment group. The average scores were calculated and the $Z$ test of location shift was performed. Parameters assessing time to pain relief were analyzed using the log-rank test for right-censored data, with the Kaplan-Meier procedure used to obtain estimates of median time to event. The time to pain half gone was analyzed in the same way (except for censoring). All reported and observed AEs were summarized; no further analysis was performed.

The first hypothesis was superiority of ibuprofen lysinate over placebo, based on the lower limit of the 95\% confidence interval (CI) for the difference in TOTPAR between the groups being greater than 0 . The second hypothesis was that ibuprofen lysinate was noninferior to ibuprofen acid, demonstrated by the two-sided 95\% CI for the treatment difference being entirely to the right of the non-inferiority margin (i.e., - 3). The third hypothesis was that ibuprofen lysinate has a superior onset of action to ibuprofen acid, shown if the lower limit of the 95\% CI for the treatment difference in PAR at $45 \mathrm{~min}$ post-dose was greater than 0 .
Hierarchical statistical testing was employed whereby subsequent analyses were conducted only if the previous hypothesis was proven using these criteria.

The primary analyses were undertaken on the intention-to-treat (ITT) population, which comprised all randomized patients who received the study medication and had at least one post-baseline measure of PAR and PI. Secondary analyses were undertaken on the perprotocol population, which included all members of the ITT set who did not have a major protocol violation. The safety analysis set comprised all patients who received the study medication.

The study was sponsored by Zentiva Group a.s., which held the data during the study. The authors had complete access to the data after unblinding. The data reported here were those available to the authors as of March 13, 2008. The study results were publicly available at https://www.clinicaltrialsregister.eu.

\section{RESULTS}

\section{Patient Disposition}

A total of 381 patients were screened, and 351 were randomized and received study medication (Fig. 1). Table 1 shows the number of patients in the predefined datasets. Baseline demographics and clinical characteristics were not significantly different between the groups (Table 2). Patients were aged $18-60$ years (mean 28 years), and the majority $(n=210$ [59.8\%]) were female (Table 2). Most patients (73.2\%) were having a single molar extracted.

\section{Efficacy}

Both active treatments reduced pain beginning at $15 \mathrm{~min}$ after administration and lasting for at least $6 \mathrm{~h}$ (Fig. 2). Both ibuprofen formulations were significantly more effective than placebo in achieving pain relief over $6 \mathrm{~h}$ (TOTPAR) and at $45 \mathrm{~min}$ post-administration (Table 3). The first primary hypothesis that ibuprofen lysinate was significantly more effective than placebo at 


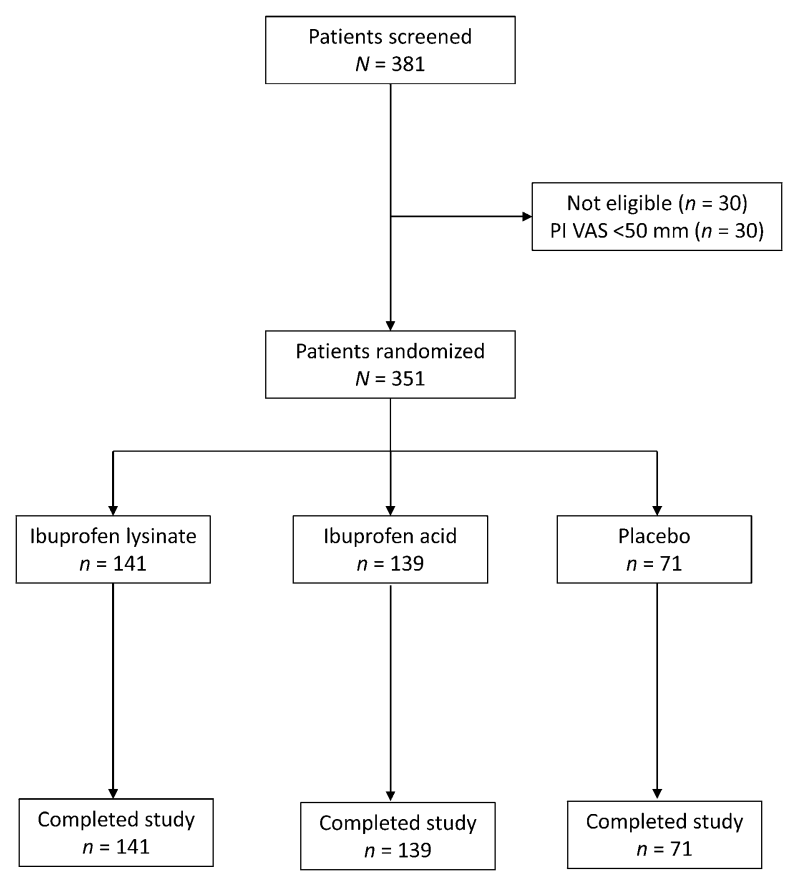

Fig. 1 Disposition of patients. PI VAS pain intensity visual analog scale

Table 1 Number of study patients in each dataset by treatment

\begin{tabular}{lcccccccc}
\hline Populations & \multicolumn{2}{l}{$\begin{array}{l}\text { Ibuprofen } \\
\text { lysinate }\end{array}$} & \multicolumn{2}{l}{$\begin{array}{l}\text { Ibuprofen } \\
\text { acid }\end{array}$} & \multicolumn{2}{c}{ Placebo } \\
\cline { 2 - 3 } randomized & $141 /$ & 100 & $139 /$ & 100 & $71 /$ & 100 \\
All & 141 & & 139 & & 71 & \\
Safety & $141 /$ & 100 & $139 /$ & 100 & $71 /$ & 100 \\
& 141 & & 139 & & 71 & \\
ITT & $140 /$ & 99.3 & $139 /$ & 100 & $71 /$ & 100 \\
& 141 & & 139 & & 71 & \\
PPS & $133 /$ & 94.3 & $126 /$ & 90.6 & $67 /$ & 94.4 \\
& 141 & & 139 & & 71 & \\
\hline
\end{tabular}

ITT intention-to-treat, PPS per-protocol set

providing pain relief over $6 \mathrm{~h}$ was demonstrated, as was the second primary hypothesis that ibuprofen lysinate was non-inferior to ibuprofen acid for pain relief over $6 \mathrm{~h}$ (Table 3). The third hypothesis (that ibuprofen lysinate was superior to ibuprofen acid for pain relief at $45 \mathrm{~min}$, and therefore associated with a more
Table 2 Demographic and other baseline characteristics

\begin{tabular}{|c|c|c|c|}
\hline & $\begin{array}{l}\text { Ibuprofen } \\
\text { lysinate } \\
N=141\end{array}$ & $\begin{array}{l}\text { Ibuprofen } \\
\text { acid } \\
N=139\end{array}$ & $\begin{array}{l}\text { Placebo } \\
N=71\end{array}$ \\
\hline \multicolumn{4}{|c|}{ Sex, $n(\%)$} \\
\hline Female & $83(58.9)$ & $87(62.6)$ & $40(56.3)$ \\
\hline Male & $58(41.1)$ & $52(37.4)$ & $31(43.7)$ \\
\hline \multicolumn{4}{|c|}{ Age, years } \\
\hline $\begin{array}{r}\text { Mean } \\
(\mathrm{SD})\end{array}$ & $28.7(7.5)$ & $28.5(8.2)$ & $27.5(7.9)$ \\
\hline Range & $18.0-60.5$ & $17.9-58.1$ & $16.0-60.0$ \\
\hline \multicolumn{4}{|c|}{ Weight, kg } \\
\hline $\begin{array}{r}\text { Mean } \\
(\mathrm{SD})\end{array}$ & $71.2(14.6)$ & $70.7(16.1)$ & $71.4(14.5)$ \\
\hline Range & $44.0-120.0$ & $46.0-140.0$ & $49.0-108.0$ \\
\hline \multicolumn{4}{|c|}{ Height, cm } \\
\hline $\begin{array}{r}\text { Mean } \\
(\mathrm{SD})\end{array}$ & $173.9(9.0)$ & $174.1(9.7)$ & $174.0(9.3)$ \\
\hline Range & $150.0-198.0$ & $155.0-200.0$ & $152.0-200.0$ \\
\hline
\end{tabular}

Baseline pain intensity (VAS), mm

$\begin{array}{rrrr}\begin{array}{r}\text { Mean } \\ (\mathrm{SD})\end{array} & 70.3(10.0) & 69.4(9.6) & 68.8(9.3) \\ \text { Range } & 51.0-99.0 & 50.0-94.0 & 51.0-90.0\end{array}$

No. of teeth extracted, $n$ (\%)

\begin{tabular}{llll}
1 & $110(78.0)$ & $97(69.8)$ & $50(70.4)$ \\
2 & $31(22.0)$ & $41(29.5)$ & $21(29.6)$ \\
3 & 0 & 0 & 0 \\
4 & 0 & $1(0.7)$ & 0 \\
\hline
\end{tabular}

$S D$ standard deviation, $V A S$ visual analog scale

rapid onset of action) was not confirmed. Similar results were obtained in the analyses of SPID and PID at 45 min (Table 3).

Fewer patients taking ibuprofen than placebo required rescue medication. In the ibuprofen lysinate and ibuprofen acid arms, 21 of 140 patients (15\%) and 20 of 139 patients $(14.4 \%)$, respectively, took rescue medication, compared with 21 of 71 patients $(29.6 \%)$ in the placebo arm. 

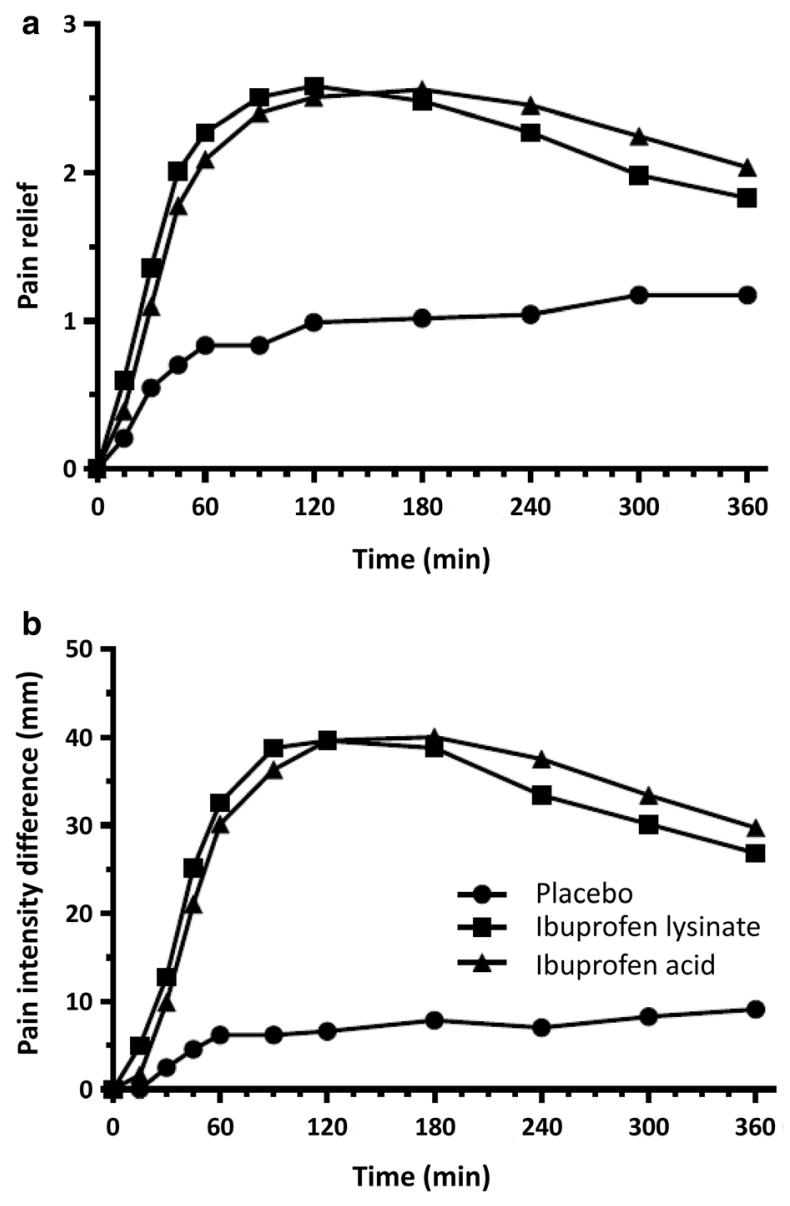

Fig. 2 Pain relief (a) and pain intensity difference (b) over time for the three treatment groups

\section{Time to Onset of Action}

Time to any pain relief, to meaningful pain relief, and to pain half gone are presented in Table 4. There was no significant difference between the two ibuprofen formulations in the time to any pain relief $(p=0.6618)$, time to meaningful pain relief $(p=0.8630)$, and time to pain half gone $(p=0.9133)$.

\section{Patient Assessment}

Patients' global assessment of efficacy showed significantly higher ratings with either of the active treatments compared with placebo ( $p<0.05$ for each comparison). Treatment was rated as "good", "very good", or "excellent" by $75.0 \%$ of patients receiving ibuprofen lysinate,
$80.5 \%$ of patients receiving ibuprofen acid, and $31.0 \%$ receiving placebo. There was no significant difference between ibuprofen lysinate and ibuprofen acid $(p>0.05)$.

\section{Safety}

All treatments were well tolerated, and all reported AEs were of mild to moderate intensity. Two patients in the ibuprofen lysinate group (1.4\%) developed edema; other AEs occurring in one patient each $(0.7 \%)$ were oral administration complication (i.e., difficulty swallowing the tablets), pain, wound complication, wound dehiscence, seroma, facial swelling, alveolar osteitis, and hematoma. Similarly, in the ibuprofen acid arm, two patients (1.4\%) developed edema and one each (0.7\%) developed procedural pain, post-procedural edema, headache, paresthesia, hypoesthesia, nausea, dysphagia, increased body temperature, epistaxis, and facial swelling. None of the AEs in either active treatment arm was considered by investigators to be treatment-related. No AEs were reported by patients receiving placebo.

\section{DISCUSSION}

Ibuprofen acid and ibuprofen lysinate comparably reduced pain after third molar extraction. While ibuprofen lysinate might have pharmacokinetic advantages over ibuprofen acid, pharmacodynamic superiority was not evident in our study. Both formulations of ibuprofen significantly relieved pain compared with placebo, whether ibuprofen was administered as a lysine salt or acid. Thus, the results of this study add more information to the already large database of clinical results demonstrating that $400 \mathrm{mg}$ ibuprofen is an effective and well-tolerated analgesic for treating postoperative pain [3]. Meta-analyses in other pain indications (acute tension-type headache and migraine) confirm the analgesic efficacy of ibuprofen $[15,16]$. Although fast-releasing ibuprofen appears to be more effective in the dental extraction model [3], this was not confirmed in our study. The non-superiority of fast-releasing ibuprofen versus ibuprofen acid has also been 
Table 3 Efficacy results

\begin{tabular}{|c|c|c|c|c|c|c|}
\hline & $\begin{array}{l}\text { Ibuprofen } \\
\text { lysinate }\end{array}$ & $\begin{array}{l}\text { Ibuprofen } \\
\text { acid }\end{array}$ & Placebo & $\begin{array}{l}\text { Ibuprofen lysinate- } \\
\text { placebo difference }\end{array}$ & $\begin{array}{l}\text { Ibuprofen acid- } \\
\text { placebo } \\
\text { difference }\end{array}$ & $\begin{array}{l}\text { Ibuprofen lysinate- } \\
\text { ibuprofen acid } \\
\text { difference }\end{array}$ \\
\hline \multicolumn{7}{|l|}{ TOTPAR } \\
\hline $\begin{array}{l}\text { Adjusted } \\
\text { mean } \\
(\mathrm{SE})\end{array}$ & $\begin{array}{l}19.57 \\
\quad(1.08)\end{array}$ & $\begin{array}{l}19.96 \\
(1.14)\end{array}$ & $\begin{array}{l}8.27 \\
\quad(1.36)\end{array}$ & $11.31(1.45)$ & $11.70(1.46)$ & $-0.39(1.20)$ \\
\hline $95 \% \mathrm{CI}$ & $\begin{array}{l}17.45 \\
21.70\end{array}$ & $\begin{array}{l}17.73 \\
22.20\end{array}$ & $\begin{array}{l}5.59 \\
10.94\end{array}$ & $8.45,14.16$ & $8.83,14.56$ & $-2.74,1.96$ \\
\hline$p$ value & & & & $<0.05$ & $<0.05$ & NS \\
\hline \multicolumn{7}{|l|}{ PAR45 } \\
\hline $\begin{array}{l}\text { Adjusted } \\
\text { mean } \\
(\mathrm{SE})\end{array}$ & $\begin{array}{l}1.92 \\
(0.13)\end{array}$ & $\begin{array}{l}1.67 \\
(0.13)\end{array}$ & $\begin{array}{l}0.62 \\
\quad(0.16)\end{array}$ & $1.29(0.17)$ & $1.04(0.17)$ & $0.25(0.14)$ \\
\hline $95 \% \mathrm{CI}$ & $\begin{array}{l}1.67 \\
2.17\end{array}$ & $\begin{array}{l}1.40 \\
1.93\end{array}$ & $\begin{array}{l}0.31 \\
0.94\end{array}$ & $0.96,1.63$ & $0.70,1.38$ & $-0.02,0.53$ \\
\hline$p$ value & & & & $<0.05$ & $<0.05$ & NS \\
\hline \multicolumn{7}{|l|}{ SPID } \\
\hline $\begin{array}{l}\text { Adjusted } \\
\text { mean } \\
(\mathrm{SE})\end{array}$ & $\begin{array}{l}272.07 \\
\quad(22.55)\end{array}$ & $\begin{array}{l}275.45 \\
\quad(23.73)\end{array}$ & $\begin{array}{l}25.17 \\
\quad(28.39)\end{array}$ & $246.90(30.31)$ & $250.28(30.41)$ & $-3.38(24.97)$ \\
\hline $95 \% \mathrm{CI}$ & $\begin{array}{l}227.72 \\
316.41\end{array}$ & $\begin{array}{l}228.77 \\
322.13\end{array}$ & $\begin{array}{r}-30.68 \\
81.02\end{array}$ & $187.29,306.51$ & $190.46,310.10$ & $-52.49,45.73$ \\
\hline$p$ value & & & & $<0.05$ & $<0.05$ & NS \\
\hline \multicolumn{7}{|l|}{ PID45 } \\
\hline $\begin{array}{l}\text { Adjusted } \\
\text { mean } \\
(\mathrm{SE})\end{array}$ & $\begin{array}{l}22.09 \\
(2.57)\end{array}$ & $\begin{array}{l}17.73 \\
(2.71)\end{array}$ & $\begin{array}{l}1.50 \\
(3.24)\end{array}$ & $20.59(3.46)$ & $16.23(3.47)$ & $4.35(2.85)$ \\
\hline $95 \% \mathrm{CI}$ & $\begin{array}{l}17.02 \\
27.15\end{array}$ & $\begin{array}{l}12.40 \\
23.06\end{array}$ & $\begin{array}{c}-4.88 \\
7.87\end{array}$ & $13.78,27.39$ & $9.40,23.06$ & $-1.25,9.96$ \\
\hline$p$ value & & & & $<0.05$ & $<0.05$ & NS \\
\hline
\end{tabular}

shown in head-to-head studies investigating analgesic effects for the treatment of headache [17].

Ibuprofen is only weakly soluble in acidic conditions (i.e., the gastric environment), and this can lead to slow absorption. Since fast absorption of an analgesic should be linked to faster onset of action, advanced pharmaceutical formulations were developed to provide fasteracting analgesics. Such formulations include 
Table 4 Median times to onset of action

\begin{tabular}{|c|c|c|c|c|c|c|}
\hline \multirow[t]{2}{*}{ Endpoint } & \multicolumn{3}{|c|}{ Median ( $95 \% \mathrm{CI}$ ) time to endpoint, minutes } & \multicolumn{3}{|c|}{$p$ value for comparisons } \\
\hline & $\begin{array}{l}\text { Ibuprofen } \\
\text { lysinate }\end{array}$ & Ibuprofen acid & Placebo & $\begin{array}{l}\text { Ibuprofen } \\
\text { lysinate- } \\
\text { placebo } \\
\text { difference }\end{array}$ & $\begin{array}{l}\text { Ibuprofen } \\
\text { acid-placebo } \\
\text { difference }\end{array}$ & $\begin{array}{l}\text { Ibuprofen } \\
\text { lysinate-ibuprofen } \\
\text { acid difference }\end{array}$ \\
\hline To any relief & $\begin{array}{l}30.0 \\
(25.0,30.0)\end{array}$ & $\begin{array}{l}30.0 \\
(30.0,40.0)\end{array}$ & $\begin{array}{l}120.0 \\
\quad(50.0,325.0)\end{array}$ & $<0.0005$ & $<0.0005$ & 0.6618 \\
\hline $\begin{array}{l}\text { To } \\
\text { meaningful } \\
\text { pain relief }\end{array}$ & $\begin{array}{l}60.0 \\
(55.0,75.0)\end{array}$ & $\begin{array}{l}65.0 \\
(60.0,90.0)\end{array}$ & $\begin{array}{l}\text { NA } \\
\qquad(280.0, N A)\end{array}$ & $<0.0005$ & $<0.0005$ & 0.8630 \\
\hline $\begin{array}{l}\text { To pain half } \\
\text { gone }\end{array}$ & $\begin{array}{l}65.6 \\
(53.1,95.0)\end{array}$ & $\begin{array}{l}71.3 \\
(57.2,96.7)\end{array}$ & $\begin{array}{l}\text { NA } \\
\qquad(\mathrm{NA}, \mathrm{NA})\end{array}$ & $<0.0005$ & $<0.0005$ & 0.9133 \\
\hline
\end{tabular}

$C I$ confidence intervals, $N A$ not able to be calculated due to the limited number of patients who experienced corresponding event

effervescent tablets, liquid capsules, or ibuprofen salts of lysine or arginine. Indeed, such formulations are absorbed faster than ibuprofen acid when taken under fasting conditions, which implies for example at least $10 \mathrm{~h}$ since the last ingestion of food. Under non-fasting conditions, however, ibuprofen lysinate is not absorbed more quickly than ibuprofen acid [18, 19].

A meta-analysis by Moore et al. [4] suggested that fast-releasing ibuprofen formulations provide stronger and faster relief of postoperative pain than ibuprofen acid, although the differences were relatively small. This analysis included head-to-head comparisons between ibuprofen acid and ibuprofen arginate or liquid formulations because no direct comparisons between ibuprofen acid and ibuprofen lysinate were available at the time [4]. Our study showed that, in the dental extraction model, ibuprofen lysinate was not more efficacious or faster-acting than ibuprofen acid based on the weighted sum of PAR and PI assessments. Thus, ibuprofen lysinate had no pharmacologic advantages over ibuprofen acid. The overall assessments of the two ibuprofen formulations by patients were also not statistically different as well, further confirming the findings of comparable efficacy.

On the other hand, the analgesic efficacy of ibuprofen can be improved by combining this compound with other analgesic compounds, such as paracetamol. Since ibuprofen and paracetamol have different mechanisms of action, combining these compounds results in higher analgesic efficacy than can be achieved with either of the single compounds alone [20,21].

Another example is the addition of caffeine to analgesics. A Cochrane meta-analysis confirmed that analgesics combined with caffeine provide more effective pain relief than analgesics without caffeine [22]. Moreover, a recent study on the efficacy and safety of the combination of $400 \mathrm{mg}$ ibuprofen acid with $100 \mathrm{mg}$ caffeine in the dental extraction model showed that this combination was more efficacious and had a faster onset of action than ibuprofen acid alone [23]. Thus, combining ibuprofen with caffeine or another analgesic agent appears to be a more efficient way to increase its analgesic activity than administering ibuprofen as a lysine salt formulation.

\section{Limitations}

The number of molars having extracted can influence the level of pain and possibly efficacy and safety. In our study, most patients were having a single molar extracted. Between the study groups, patients with one or two tooth extractions did not differ significantly and thus the effects on efficacy and safety were considered to be balanced. 


\section{CONCLUSIONS}

A single dose of ibuprofen lysinate formulation has similar analgesic efficacy and onset of action as ibuprofen acid in patients who have recently undergone third molar extraction, and the two formulations are similarly well tolerated.

\section{ACKNOWLEDGEMENTS}

We would like to thank all of the investigators for their support.

Funding. Sponsorship for the development of this manuscript and the Rapid Service Fee were funded by Sanofi-Aventis Deutschland $\mathrm{GmbH}$. Sanofi took over the consumer healthcare business from Zentiva group a.s.

Medical Writing Assistance. Catherine Rees of Springer Healthcare Communications edited this manuscript prior to submission. This medical editing assistance was funded by SanofiAventis Deutschland GmbH.

Authorship. All named authors meet the International Committee of Medical Journal Editors (ICMJE) criteria for authorship for this article, take responsibility for the integrity of the work as a whole, and have given their approval for this version to be published.

Authorship Contributions. Anette Lampert participated in data interpretation, read, discussed, and approved drafts of the manuscript. Thomas Weiser participated in data interpretation and discussion, drafted, read, and approved the manuscript. Eva Koscova participated in data acquisition, data interpretation, and critical review and approval of the manuscript drafts. Ján Kyselovič extracted data from the clinical trial report, conducted a literature search, critically reviewed and approved the drafts of the manuscript.

Disclosures. Anette Lampert and Thomas Weiser are employees of Sanofi-Aventis Deutschland GmbH. Eva Koscova is an employee of Sanofi-Aventis Pharma Slovakia s.r.o. Ján Kyselovič has nothing to disclose.

Compliance with Ethics Guidelines. All procedures were conducted in accordance with the ethical principles of the Declaration of Helsinki, International Committee on Harmonisation Good Clinical Practice Guidelines of 1997, and applicable national laws. The study began only when all the requirements of the appropriate regulatory authority had been fulfilled, and the study protocol had been approved by local ethics committees (see Supplementary Material). Informed consent was obtained from all patients included in the study.

Data Availability. The datasets generated during and/or analyzed during the current analysis are available from the corresponding author on reasonable request.

Open Access. This article is distributed under the terms of the Creative Commons Attribution-NonCommercial 4.0 International License (http://creativecommons.org/licenses/ by-nc/4.0/), which permits any noncommercial use, distribution, and reproduction in any medium, provided you give appropriate credit to the original author(s) and the source, provide a link to the Creative Commons license, and indicate if changes were made.

\section{REFERENCES}

1. Blondell RD, Azadfard M, Wisniewski AM. Pharmacologic therapy for acute pain. Am Fam Physician. 2013;87(11):766-72.

2. Duong M, Salvo F, Pariente A, Abouelfath A, Lassalle R, Droz C, et al. Usage patterns of 'over-thecounter' vs. prescription-strength nonsteroidal anti-inflammatory drugs in France. Br J Clin Pharmacol. 2014;77(5):887-95.

3. Moore RA, Derry S, Aldington D, Wiffen PJ. Single dose oral analgesics for acute postoperative pain in adults-an overview of Cochrane reviews. Cochrane Database Syst Rev. 2015;(9):CD008659. https://doi. org/10.1002/14651858.CD008659.pub3. 
4. Moore RA, Derry S, Straube S, Ireson-Paine J, Wiffen PJ. Faster, higher, stronger? Evidence for formulation and efficacy for ibuprofen in acute pain. Pain. 2014;155(1):14-21.

5. Moore RA, Derry S, Straube S, Ireson-Paine J, Wiffen PJ. Validating speed of onset as a key component of good analgesic response in acute pain. Eur J Pain. 2015;19(2):187-92.

6. Irvine J, Afrose A, Islam N. Formulation and delivery strategies of ibuprofen: challenges and opportunities. Drug Dev Ind Pharm. 2018;44(2):173-83.

7. Moore RA, Derry S, Wiffen PJ, Straube S. Effects of food on pharmacokinetics of immediate release oral formulations of aspirin, dipyrone, paracetamol and NSAIDs-a systematic review. Br J Clin Pharmacol. 2015;80(3):381-8.

8. Au AH, Choi SW, Cheung CW, Leung YY. The efficacy and clinical safety of various analgesic combinations for post-operative pain after third molar surgery: a systematic review and meta-analysis. PLoS One. 2015;10(6):e0127611.

9. Cooper SA, Desjardins PJ. The value of the dental impaction pain model in drug development. Methods Mol Biol. 2010;617:175-90.

10. Cooper SA, Desjardins PJ, Turk DC, Dworkin RH, Katz NP, Kehlet $H$, et al. Research design considerations for single-dose analgesic clinical trials in acute pain: IMMPACT recommendations. Pain. 2016;157(2):288-301.

11. Black P, Max MB, Desjardins P, Norwood T, Ardia A, Pallotta T. A randomized, double-blind, placebocontrolled comparison of the analgesic efficacy, onset of action, and tolerability of ibuprofen arginate and ibuprofen in postoperative dental pain. Clin Ther. 2002;24(7):1072-89.

12. Desjardins P, Black P, Papageorge M, Norwood T, Shen DD, Norris L, et al. Ibuprofen arginate provides effective relief from postoperative dental pain with a more rapid onset of action than ibuprofen. Eur J Clin Pharmacol. 2002;58(6):387-94.

13. Mehlisch DR, Ardia A, Pallotta T. A controlled comparative study of ibuprofen arginate versus conventional ibuprofen in the treatment of postoperative dental pain. J Clin Pharmacol. 2002;42(8):904-11.

14. Mehlisch DR, Jasper RD, Brown P, Korn SH, McCarroll K, Murakami AA. Comparative study of ibuprofen lysine and acetaminophen in patients with postoperative dental pain. Clin Ther. 1995;17(5):852-60.
15. Derry S, Wiffen PJ, Moore RA, Bendtsen L. Ibuprofen for acute treatment of episodic tension-type headache in adults. Cochrane Database Syst Rev. 2015;(7):CD011474. https://doi.org/10.1002/ 14651858.CD011474.pub2.

16. Rabbie R, Derry S, Moore RA. Ibuprofen with or without an antiemetic for acute migraine headaches in adults. Cochrane Database Syst Rev. 2013;(4):CD008039. https://doi.org/10.1002/ 14651858.CD008039.pub3.

17. Heintze K, Fuchs W. Effects of food on pharmacokinetics of immediate release oral formulations. Br J Clin Pharmacol. 2015;80(5):1239.

18. Klueglich M, Ring A, Scheuerer S, Trommeshauser D, Schuijt C, Liepold B, et al. Ibuprofen extrudate, a novel, rapidly dissolving ibuprofen formulation: relative bioavailability compared to ibuprofen lysinate and regular ibuprofen, and food effect on all formulations. J Clin Pharmacol. 2005;45(9):1055-61.

19. Weiser T, Schepers C, Muck T, Lange R. Pharmacokinetic properties of ibuprofen (IBU) from the fixed-dose combination IBU/caffeine (400/100 mg; FDC) in comparison with $400 \mathrm{mg}$ IBU as acid or lysinate under fasted and fed conditions-data from 2 single-center, single-dose, randomized crossover studies in healthy volunteers. Clin Pharmacol Drug Dev. 2019;8(6):742-53.

20. Mehlisch DR, Aspley S, Daniels SE, Bandy DP. Comparison of the analgesic efficacy of concurrent ibuprofen and paracetamol with ibuprofen or paracetamol alone in the management of moderate to severe acute postoperative dental pain in adolescents and adults: a randomized, double-blind, placebo-controlled, parallel-group, single-dose, two-center, modified factorial study. Clin Ther. 2010;32(5):882-95.

21. Mehlisch DR, Aspley S, Daniels SE, Southerden KA, Christensen KS. A single-tablet fixed-dose combination of racemic ibuprofen/paracetamol in the management of moderate to severe postoperative dental pain in adult and adolescent patients: a multicenter, two-stage, randomized, double-blind, parallel-group, placebo-controlled, factorial study. Clin Ther. 2010;32(6):1033-49.

22. Derry CJ, Derry S, Moore RA. Caffeine as an analgesic adjuvant for acute pain in adults. Cochrane Database Syst Rev. 2014;(12):CD009281. https:// doi.org/10.1002/14651858.CD009281.pub3.

23. Weiser T, Richter E, Hegewisch A, Muse DD, Lange R. Efficacy and safety of a fixed-dose combination of ibuprofen and caffeine in the management of moderate to severe dental pain after third molar extraction. Eur J Pain. 2018;22(1):28-38. 